\title{
Analyzing the Representation of Communicative Activities in Grade 12 English Textbook at Tebela Secondary and Preparatory School
}

\author{
Tesfaye Buche Bosha \\ College of Social Sciences and Humanities Department of English Language and Literature, Wolaita Sodo \\ University, Sodo Ethiopia
}

\begin{abstract}
The purpose of this study was analyzing the representation of communicative activities in grade 12 English textbook at Tebela Secondary and Preparatory School. Descriptive research design was employed for the current study. To collect the necessary data for the study, semi-structured interview for two teachers, questionnaire for sixty-five students and document analysis were employed. To analyze the collected data, qualitative and quantitative methods of data analysis were employed. That is, data collected through questionnaire were analyzed employing statistical tools such as frequency and percentage using SPSS version 20, while responses obtained from interview were described and discussed. In addition, the data obtained from document analysis that were presented in tables and explained qualitatively to validate and triangulate the data obtained from interview and questionnaire. From the analysis of data, different findings were obtained. The study revealed that that different communicative contents and activities were found in Grade 12 English Textbook as confirmed by three different results, which are based on questionnaire data from students, semi structured interview data from two English teachers and data from document analysis. This doesn't mean that the availability of communicative contents and activities can make English language teaching and learning effective and only the availability can't make the Textbook appropriate to students, because the contents and activities should be organized and designed sequentially. Based on the findings, conclusions were drawn and recommendations were forwarded to improve the perceptions of teachers and students as well as to revise some contents of the textbook.
\end{abstract}

Keywords: Communicative Contents, Communicative Activities and Textbook Representation

DOI: $10.7176 / J L L L / 73-02$

Publication date: November $30^{\text {th }} 2020$

\section{Introduction}

The textbook plays pivotal role in teaching and learning. It has priceless contribution for teaching and learning language skills. Besides, textbook has a lot of advantages so that different scholars on the area stated the role of textbook in language teaching and learning. For instance, Graves (2000:175) states:

Textbook provides a syllabus for the course because the authors of the syllabus have made decisions about what will be learned and in what order, it provides security for the students because they have a kind of a road map of the course: they know what to expect and they know what is expected from them, it provides a set of visuals, activities, readings, etc., and so saves the teacher time in finding or developing such materials, it provides teachers with a basis for assessing students' learning. Some textbooks include tests or evaluation tools; it may include supporting materials (teacher's guide, $c d$, worksheets, and video.), it provides consistency within a program across a given level, if all teachers use the same textbook, and if textbooks follow a sequence, as within a series, it provides consistency between levels.

Likewise, Cunnings worth (1995) argues that textbooks are an effective resource for self-directed learning, an effective resource for presentation material, a source of ideas and activities, and a reference source for students, a syllabus where they reflect pre-determined learning objectives, and support for less experienced teachers who have yet to gain in confidence. Finally, Hutchinson and Torres (1994) have pointed out that textbooks may play a pivotal role in innovation. They suggest that textbooks can support teachers through potentially disturbing and threatening change processes, demonstrate new and/or untried methodologies, introduce change gradually, and create scaffolding upon which teachers can build a more creative methodology of their own.

Furthermore, Richards (2001) states that textbooks act as a key component in most language programs. They provide the learners with the necessary input that the learners receive and the language practice that occurs in the class. They also serve as the basis for the language content and skills to be taught and other kinds of language practice that the learners take part in. Regarding the advantages, Richards (2001) states that without textbooks a program may have no path, therefore they provide structure and a syllabus. Besides, the use of a textbook in a program can guarantee that students in different classes will receive a similar content and therefore can be evaluated in the same way. In other words, textbooks provide the standards in instruction. Moreover, they 
include a variety of learning resources such as workbooks, cassettes, videos, etc., which makes the learning environment interesting and enjoyable for the learners. As for inexperienced teachers, Richards (2001) states that textbooks can serve as a tool to train them. Finally, he concludes that textbooks are efficient in that they allow much time for the teacher to focus on teaching rather than material's production.

As it is mentioned in the above from different perspectives of scholars, textbook has lion's share in language teaching and learning. It is essential for experienced teachers, inexperienced teachers and students. Therefore, the current study focused on the role of English for grade 12 textbook in enhancing the communicative competence of students.

\section{Statement of the Problem}

Jones (1999) "there is a need to evaluate language teaching methods, materials, and effectiveness as teachers and also how materials are presented to learners, the types of learning tasks used and the way the courses are designed. They are all part of the curriculum taking place both prior to, and during the implementation of a learning program and they all must be evaluated." He also defines evaluation 'as the means by which we can gain a better understanding of what's effective, what's less effective and what appears to be no use at all.

In an empirical point of view, Hutchinson and Waters (1987, p. 96) see evaluation plainly as "a matter of judging the fitness of something for a particular purpose." They share with Tomlinson $(2008$, p. 105) that "the evaluation process should be systematic" and add that it "is best seen as a matching exercise: matching your analyzed needs to available solutions." The essence of this definition is its attention to the students' needs in evaluating materials and therefore is adopted in this thesis. Since English learners and teachers use textbooks in their classrooms, it is more preferable if the teacher and student involved in the process of evaluation in order to be provided with the relevant textbook for their specific learner group. Their views on the usefulness and effectiveness of the textbooks are also worth scrutinizing their textbooks, so as to identify the weak and strong points in relation to their own teaching situation. This is required because selecting textbooks involves matching the material to the context where it is going to be used, and a wide range of specialists share the view that no textbook that is designed for a general market will be absolutely appropriate and ideal for one's particular group of learners. As Grant (1987) claims 'Perfect book does not exist', yet the aim is to be able to find out the best possible one that will fit and be appropriate to a particular learner group. The reasons for materials evaluation activities are many and varied. One of the major reasons is the need to adapt new course books. Another reason as Cunningsworth (1995) emphasized is to identify particular strengths and weaknesses in course books already in use.

According to my reading, there were some studies conducted on the same area. For example, Hailu Kebede (2011) conducted a study on an exploration of teaching oral skills in English through communicative activities. He used descriptive survey method to achieve the objectives of the study, he employed questionnaire, classroom observation, interviews and content analysis as data gathering tools. The findings of the study revealed that teachers and students did not play their roles as stated by modern methods such as the communicative language learning and teaching. The researcher also revealed major factors that inhibit students 'oral communication such as lack of authentic communicative activities, lack of well-organized programs for oral communication, students' fear of making mistake and teachers' method of teaching.

Moreover, Lakachew Mulat (2003) conducted a research on teachers' attitude towards communicative language teaching and practical problem in its implementation. He employed descriptive research design to attain the objectives of the study and used questionnaires, interviews and observation as data gathering tool. The finding of the study indicated that teachers generally have mildly favorable (positive) attitudes towards communicative language teaching, they, however, articulated a number of constraints that hamper the effective accomplishment of communicative language teaching as planned.

Furthermore, Melaku Dumessa (2002) conducted a study on an investigation English language Teachers' Reading Lesson Presentation in terms of the new course book for grade nine. He employed descriptive research method, questionnaires and observation as data gathering tools as well as he analyzed data using descriptive statistics such as frequency and percentage. The finding of his study revealed that most the subjects rarely or never present reading lessons incline with the procedures prescribed in the new Teacher's book. Besides, the study depicted that English teachers' reading lesson presentation practice was dominated by traditional approach of teaching reading.

Therefore, the current study focused on the analyzing the representation of communicative activities in Grade 12 English textbook at Tebela Secondary and Preparatory School. It attempted to examine communicative contents and activities as well as to analyze the proportion of communicative activities represented in the textbook. 


\section{Research Design and Methodology \\ 3.1 Design of the Study}

According to Kothari (2004), descriptive research studies are those studies, which are concerned with describing the characteristics of a particular individual or of group. Since the current study was analyzing the representation of communicative activities in Grade 12 English textbook at Tebela Secondary and Preparatory School, descriptive design was appropriate to describe the representation of communicative contents and activities in grade 12 English textbook. Regarding to research method, the researcher employed both qualitative and quantitative methods.

\subsection{Research setting}

The study was conducted in Tebela Preparatory School, particularly in grade 12, which was located in Southern Nations Nationalities and People Regional State in Wolaita Zone in Tebela City.

\subsection{Participants of the Study}

Sampling is important when the population of the study is large and difficult to manage it due to different reasons. But here, in the selected school the number of population was sixty-five. This number was manageable regardless of time, cost and human resource. With respect to this, Kothari (2004) states that a complete numeration of the items in the population is known as a census inquiry. It can be presumed that in such an inquiry when all the items are covered no element of chance left and highest accuracy is obtained. Accordingly, all 65 were taken as the participants of the study. In addition, there were two English language teachers in the selected preparatory school. Thus, both of them were included in the study because it was believed that they can provide the data needed for this study. Both grade 12 students and teachers were selected intentionally; because when grade 12 students join university, they were expected to read a lot of courses in English as well as they made a lot of presentations in English so that they should have communicative abilities. Accordingly, it was believed that the students can have adequate information about the textbook. Besides, they were mature enough than other grades in high school level, so they could make balanced judgement about the textbook.

\subsection{Data Collection Instruments}

Three data collection instruments were used to gather the necessary data for this study. These are questionnaire, semi-structured interview and document analysis.

\subsection{Data collection procedures}

In this study, data were collected via questionnaire, semi-structured interview and document analysis. As it is mentioned earlier, the subject of the study was all Wolaita Tebela grade 12 students and their English teachers due to relevant and adequate data for the purpose of this study. The researcher assisted students during the completion of questions so that he could not administer interview at the same time. Therefore, the researcher administered data gathering tools at different time. First, data from students via questionnaire were collected. Next, the researcher administered interview to two English teachers of Tebela preparatory school. Finally, data from grade 12 English textbook were collected.

\subsection{Method of Data Analysis}

Data that were collected via the above tools were analyzed by using various methods. In this study, the quantitative data were collected from the respondents through open ended and close-ended questions of the questionnaire were analyzed quantitatively and statically described using frequency and percentage. Regarding to the data that were gathered using interview, first the researcher transcribed recorded data, then the researcherselected data relevant to the objectives of the study through reading the general idea. Next, the selected data were categorized thematically to answer the research questions in meaningful way. Furthermore, the data from textbook were collected, were summarized using frequency and percentage. Then, the proportion and percentage of communicative contents and communicative activities were compared and contrasted with the other contents and activities included in the textbook. The results of comparison and contrasts were summarized using numbers and percentage. Then, the results were described qualitatively using sentences and expressions.

\section{Analysis and Discussion of Results}

\subsection{The Results of Content Analysis on the Communicative Contents and Activities Presented in Grade 12 English Textbook}

The material used for the examination purposes in this study was the textbook entitled "English for Ethiopian Grade 12 Students' Textbook" for preparatory students (MOE, 2003). It was published in England by Pearson Education Ltd. This book, which has altogether 314 pages, consists of twelve units and four revision units. Each of the units consisted of the following parts such as listening, speaking, reading, writing, increase your 
vocabulary which is mainly focus on Vocabularies, and Language focus which is mainly focus on different Grammar lessons. The existing students' textbook, which is Grade 12 English Textbook, was examined with a purpose of verifying the data that have been gathered through questionnaire and semi-structured interview. Accordingly, the result of the textbook analysis shows that various communicative contents and activities are included in Grade 12 English Textbook. The next table shows that the communicative contents and activities included in the Textbook.

Table 1: The availability of different communicative contents and activities in the Textbook

\begin{tabular}{|l|l|l|l|}
\hline NO. & Types of communicative contents and activities & Availability & \multicolumn{1}{|c|}{ Units } \\
\hline 1 & Functional & & In all units, except 4 and 12 \\
\hline 2 & Social interaction & & In all units \\
\hline 3 & To enhance linguistic abilities & & In all units \\
\hline 4 & To enhance socio-linguistic abilities & & $1,2,3,7,8,9,10$, and 11 \\
\hline 5 & To enhance discourse abilities & & 1,3, and 10 \\
\hline 6 & To enhance strategic abilities & 2 and 3 \\
\hline 7 & To perform different functions & In all units, except unit 12 \\
\hline
\end{tabular}

As it can be seen from table 1, different communicative contents and activities are found in Grade 12 English Textbook. First, the functional communicative contents and activities such as picture narration activities, picture identification activities, find the difference activities and interview activities are found in ten units of the textbook that means except two units of the Textbook students can get functional communicative contents and activities in every unit of the Textbook. Second, social interaction communicative contents and activities namely: role play activities, discussion/debate activities, dialogue/conversation activities, storytelling activities and language games activities are found in each unit of Grade 12 English Textbook. Third, different activities that cultivate students' linguistic abilities are found in all units of the Textbook. The communicative contents and activities that cultivate communicative abilities of students found in Grade 12 English Textbook are grammar activities, pronunciation activities, stress, rhythm and intonation activities, spelling rules activities, and word formation activities like initials, prefixes and suffixes. Forth, different communicative contents and activities that enhance socio-linguistic abilities of students are found in unit one, two, three, seven, eight, nine, ten, and eleven of Grade 12 English Textbook. These activities of grammatical forms and functions, contents and activities help students to use stress and intonation to express attitude and emotion and contents and activities that help students to use the language appropriate to the culture.

Furthermore, the communicative contents and activities that enhance students' discourse abilities, strategic abilities, contents, and activities that help students to perform different functions are presented in Grade 12 English Textbook. The communicative contents and activities that can enhance discourse abilities of students are activities of taking turn, activities of cohesive devices, activities of opening and closing conversations and contents and activities that help students to produce contextualized spoken language.

Besides, the communicative contents and activities that enhance the strategic abilities of students are found in unit two and three of Grade 12 English Textbook. They are contents and activities that encourage students to take risk in using spoken language and contents and activities that help students to use different communication strategies. Finally, different communicative contents and activities that enhance students' oral communication skills in order to perform different functions of language are found in all units of Grade 12 English Textbook. Communicative functions are classified into six different classifications such as personal functions, interpersonal functions, directive functions, imaginative functions, referential functions and academic functions. Therefore, it is possible to substantiate the data from students via questionnaire, from teachers via semi-structured interview based on the results of content analysis regarding the question whether the communicative contents and activities are available or not. Thus, different communicative contents and activities are available in Grade 12 English Textbook.

In conclusion, it can be concluded that different communicative contents and activities are found in Grade 12 English Textbook as confirmed by three different results, which are based on questionnaire data from students, semi structured interview data from two English teachers and data from document analysis. This doesn't mean that the availability of communicative contents and activities can make English language teaching and learning effective and only the availability can't make the Textbook appropriate to students, because the contents and activities should be organized and designed sequentially. Therefore, the results of organization and sequence of communicative contents and activities in Grade 12 English Textbook are presented below. 
Table2: The Results of Content Analysis on the Communicative Contents and Activities Presented in Grade 12 English Textbook that Considered Different Communicative Functions

\begin{tabular}{|l|l|r|r|r|r|r|r|r|r|r|r|r|r|}
\hline No. & Types of activities & U1 & U2 & U3 & U4 & U5 & U6 & U7 & U8 & U9 & U10 & U11 & U12 \\
\hline 1 & Picture narration & $\checkmark$ & $\checkmark$ & $\checkmark$ & & & & $\checkmark$ & $\checkmark$ & $\checkmark$ & $\checkmark$ & & \\
\hline 2 & Picture identification & & $\checkmark$ & $\checkmark$ & & & $\checkmark$ & & & & $\checkmark$ & & \\
\hline 3 & Find the difference & $\checkmark$ & $\checkmark$ & $\checkmark$ & & $\checkmark$ & & $\checkmark$ & $\checkmark$ & $\checkmark$ & & & \\
\hline 4 & Interview & & & $\checkmark$ & & & & $\checkmark$ & & & & $\checkmark$ & \\
\hline
\end{tabular}

As it is seen in table 2, there different communicative contents and activities in different Units of Grade 12 English Textbook that cultivate students' oral communication skills to perform different communicative and academic functions. Different scholars, for example, Finocchiaro @ Brumfit (1983), Chamot @ O’Malley (1994) and O'Malley@ Pierce (1996) adapted by D.Tedick, categorized communicative and academic functions into six namely: personal functions, interpersonal functions, directive functions, imaginative functions and referential functions and academic functions.

First, some of communicative contents and activities that cultivate students' oral communication skills to perform personal functions of communication are presented in Unit one, four, five and six of Grade 12 English Textbook. Accordingly, personal functions of communication refers to clarifying or arranging one's ideas, expressing one's thoughts or feelings (love, joy, pleasure, happiness, surprise, likes and dislikes, satisfaction, disappointment, distress, pain, anger, anguish, fear, anxiety, sorrow, frustration, annoyance at missed opportunities, etc.), expressing moral, intellectual, and social concerns, expressing the everyday feelings of hunger, thirst, fatigue, sleepiness, cold, and warmth, but the contents and activities presented in Textbook didn't contain these all functions of communication, they are not organized sequentially and are not supported by adequate sample examples to practice and facilitate for practical use of communication.

Second, some of communicative contents and activities that cultivate students' oral communication skills to perform interpersonal functions of communication are found in unit three and four of Grade 12 English Textbook. Accordingly, interpersonal functions of communication refers to greetings and leave-takings, introducing people to others, identifying oneself to others, expressing joy at another's success (or disappointment at another's misfortune), expressing concern for other people's welfare, extending and accepting invitations, refusing invitations politely or making alternative arrangements, making appointments for meetings, breaking appointments politely and arranging another mutually convenient time, apologizing, excusing oneself and accepting excuses for not meeting commitments, indicating agreement or disagreement, interrupting another speaker politely, changing an embarrassing subject, receiving visitors and paying visits to others, arguing or debating, offering food or drinks and accepting or declining such offers politely, sharing wishes, hopes, desires, problems, beliefs, thoughts, opinions, etc., asking about others' wishes, hopes, desires, problems, beliefs, thoughts, opinions, etc., making promises and committing oneself to some action, complimenting someone and making excuses, but the communicative contents and activities in Grade 12 English Textbook couldn't cultivate students' oral communication skills to perform these all functions of communication, except few functions of communication from mentioned.

Third, some of communicative contents and activities that cultivate students' oral communication skills to perform directive functions of communication were presented in unit six and seven of Grade 12 English Textbook. Accordingly, directive functions of communication refers to accepting or refusing direction, making suggestions in which the speaker is included, persuading someone to change his/her point of view, requesting and granting permission, requesting information, asking for help and responding to a plea for help, forbidding someone to do something; issuing a command, giving and responding to instructions or directions, warning someone, discouraging someone from pursuing a course of action, establishing guidelines and deadlines for the completion of actions, asking for directions or instructions, but the communicative contents and activities in the Textbook didn't include sample activities for these all directive functions of communication.

Forth, some of communicative contents and activities that cultivate students' oral communication skills to perform referential functions of communication were presented in unit five, seven and eight. Accordingly, referential functions of communication refers to talking or reporting about things, actions, events, or people in the environment, identifying items or people in the classroom, the school, the home, the community, asking for a description of someone or something, describing someone or something, understanding messages or descriptions, creating questions, scanning or skimming for information, paraphrasing, summarizing, or translating (L1 to L2 or vice versa), interpreting information, explaining or asking for explanations of how something works, comparing or contrasting things, discussing possibilities, probabilities, or capabilities of doing something, requesting or reporting facts about events or actions or about a text, hypothesizing, formulating and supporting opinions and evaluating the results of an action or an event, but the contents and activities in the Textbook couldn't cultivate students' oral communication skills to perform these all functions of communication, except few.

Fifth, some of communicative contents and activities that cultivate students' oral communication skills to 
perform imaginative functions of communication were presented in unit one, two, four, eight and eleven. Accordingly, imaginative functions of communication refer to discussing a poem, a story, a text, an advertisement, a piece of music, a play, a painting, a film, a TV program, etc., story-telling, narrating events, experiencing and/or discussing a simulation (e.g., of an historical event), expanding ideas suggested by others or by a piece of reading, creating rhymes, poetry, stories, plays, or scripts, recombining familiar dialogues or passages creatively, suggesting original beginnings or endings to dialogues or stories, solving problems or mysteries, but these contents and activities are not included in the Textbook, except some of the contents and activities.

Lastly, some of the communicative contents and activities that cultivate students' oral communication skills to perform academic functions were presented in unit six, nine and ten. Accordingly, academic functions refer to seeking information/informing: observe and explore the environment, acquire information, inquire, identify, report, or describe information, informing: recount information provided by a teacher/text; retell a story or personal experience, comparing: describe similarities and differences in objects or ideas, ordering: sequence objects, ideas, events, classifying: group objects or ideas according to their characteristics, analyzing: separate whole into parts; identify relationships and patterns, inferring: make inferences, predict implications, hypothesize, justifying and persuading: give reasons for an action, decision, point of view; convince others, solving problems: define/present a problem and determine a solution, synthesizing: combine or integrate ideas to form a whole, and evaluating: assess and verify worth of an object, idea or decision, but most these are not presented in the Textbook; however, they have great roles to develop students oral communication skills.

In conclusion, more of students as well as two are not interested in the communicative contents and activities in Grade 12 English Textbook that help students to perform communicative and academic functions. This is also substantiated by the results of content analysis. The content analysis shows that a few communicative contents and activities are presented in Grade 12 English Textbook, not only that but also the existing communicative contents and activities are not supported by adequate and authentic examples.

Table3: The Results of Content Analysis on the Functional Communicative Contents and Activities Presented in Grade 12 English Textbook

\begin{tabular}{|l|l|l|l|l|l|l|l|l|l|l|l|l|l|}
\hline No. & Types of activities & U1 & U2 & U3 & U4 & U5 & U6 & U7 & U8 & U9 & U10 & U11 & U12 \\
\hline 1 & Picture narration & & & & & & & & & & & & \\
\hline 2 & Picture identification & & & & & & & & & & & & \\
\hline 3 & Find the difference & & & & & & & & & & & & \\
\hline 4 & Interview & & & & & & & & & & & & \\
\hline
\end{tabular}

The functional communicative contents and activities are analyzed above in table 3 . As it can be seen from Table 3, the picture narration communicative contents and activities and find, the difference communicative contents and activities were represented in seven different units. When they are compared with other functional communicative contents and activities in Grade 12 English Textbook, they are presented more than others. The picture identification communicative contents and activities are presented less comparing to picture narration and find the difference communicative contents and activities in Grade 12 English Textbook, whereas the interview communicative contents and activities are presented least in comparison with others.

As indicated in the results of content analysis presented in table 3 , different picture identification communicative contents and activities are represented in Grade 12 English Textbook, which are found in unit 2, 3, 6 and 10. According to Little wood (1981), in picture identification activities, Students are given pictures to describe what is in the pictures. To accomplish this activity, they can form groups and each group is given a different picture. Then students discuss the picture within their groups. Finally, the spokesperson for each group will describe it to the whole class. This fosters students' creativity, imagination and their public speaking skills. This activity can be practiced in pairs with similar pictures, but containing a number of distinguishing features, like color, size, place etc. Therefore, English Textbooks should include different picture identification activities so as to develop students' creative, imaginative and public speaking skills.

As other English Textbooks, one of the purposes of Grade 12 English Textbook is to enhance students' creative, imaginative and public speaking skills. As a result, this study examined Picture Identification activities in the Textbook as follows: some picture identification activities are found in the Textbook and they are good to develop students' oral communication skills. However, the role of picture identification activities in enhancing the communicative abilities of students is unquestionable, some of the activities found in the Textbook are not well organized, not adequate, not relevant to the Grade level and do not consider different levels of achievers. 


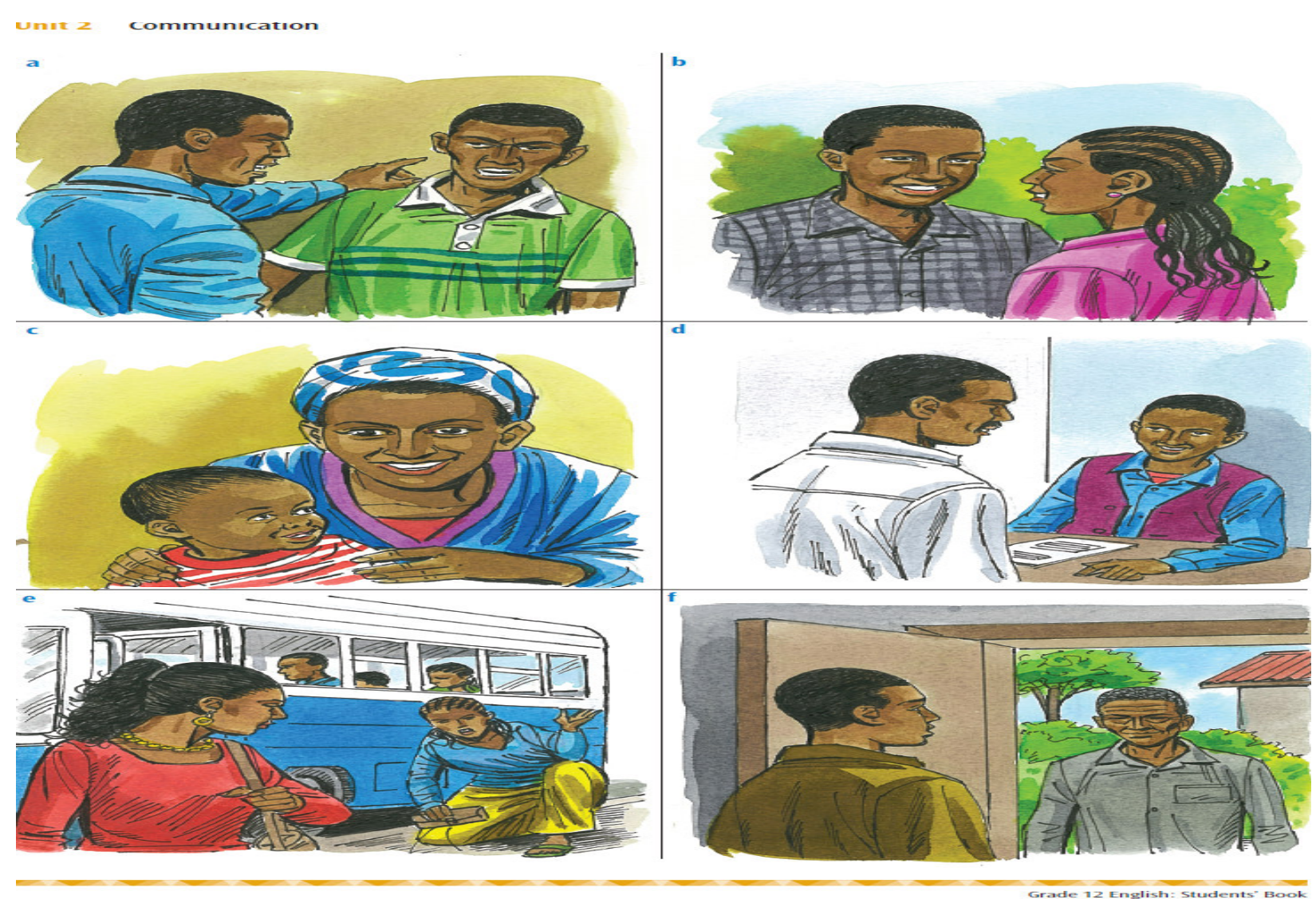

\section{Extracted from Grade 12 English Textbook page 32}

For example, pic.3, presented above is extracted from Grade 12 English Textbook that is presented as one of picture identification activities in Grade 12 English Textbook which is found on page 32, in unit 2. As it can be seen from pic. 3 above, there are six different pictures of people who are engaged in six different jobs and they are communicating according to their jobs. Here, students are asked to listen the passage which describes the way of communication in different jobs, and then to describe the job each person does. This is very simple activity and it is not appropriate to the Grade level, because what they are doing in the picture is clearly seen from the picture identification activity so that students can match easily with the word descriptions of the text. But, Grade 12 students are expected to describe the pictures themselves using their own words. Besides, another evidence is also presented below that can be taken as weakness of picture identification communicative contents and activities in Grade 12 English Textbook

\section{Work with a partner. Identify the meanings of these gestures.}

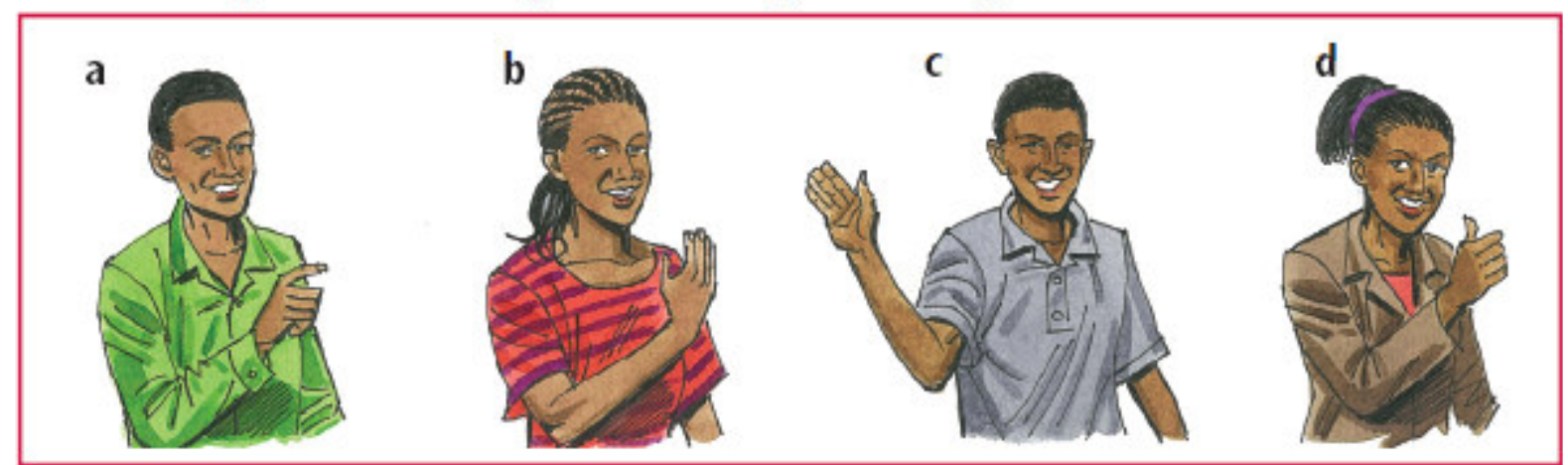

Extracted from Grade 12 English Textbook page 50

The above picture identification activity is taken from Grade 12 English Textbook which is found on page 50 , in unit 2. As it can be seen from the given picture identification activity, there are four people who are expressing their feelings using body language. In this picture identification communicative activity, Grade 12 students are asked to tell the meanings of gestures that the pictures represent to, but the gestures are very simple so that it is easy to guess their meaning. Since they are very common kind of gestures, they cannot enhance the 
oral communication skills of students and they do not motivate students to engage in picture identification activities so far.

Furthermore, there are a few picture identification functional communicative activities those are well organized, logically sequenced and fit the level, but others have the problems of organization, sequence and appropriateness to the age and grade level of students. For example, the picture identification which is presented in Grade 12 English Textbook on page 74 have the problem of appropriateness to the age and grade level of students. This activity asked students to listen to their teacher who read the passage, and then to identify which is talked about.

In modern times there have been great changes to traditional ways of life. You are going to hear one person's views about a modern development which has had a big impact.

\section{Listen to your teacher and decide which of the following is being talked about.}
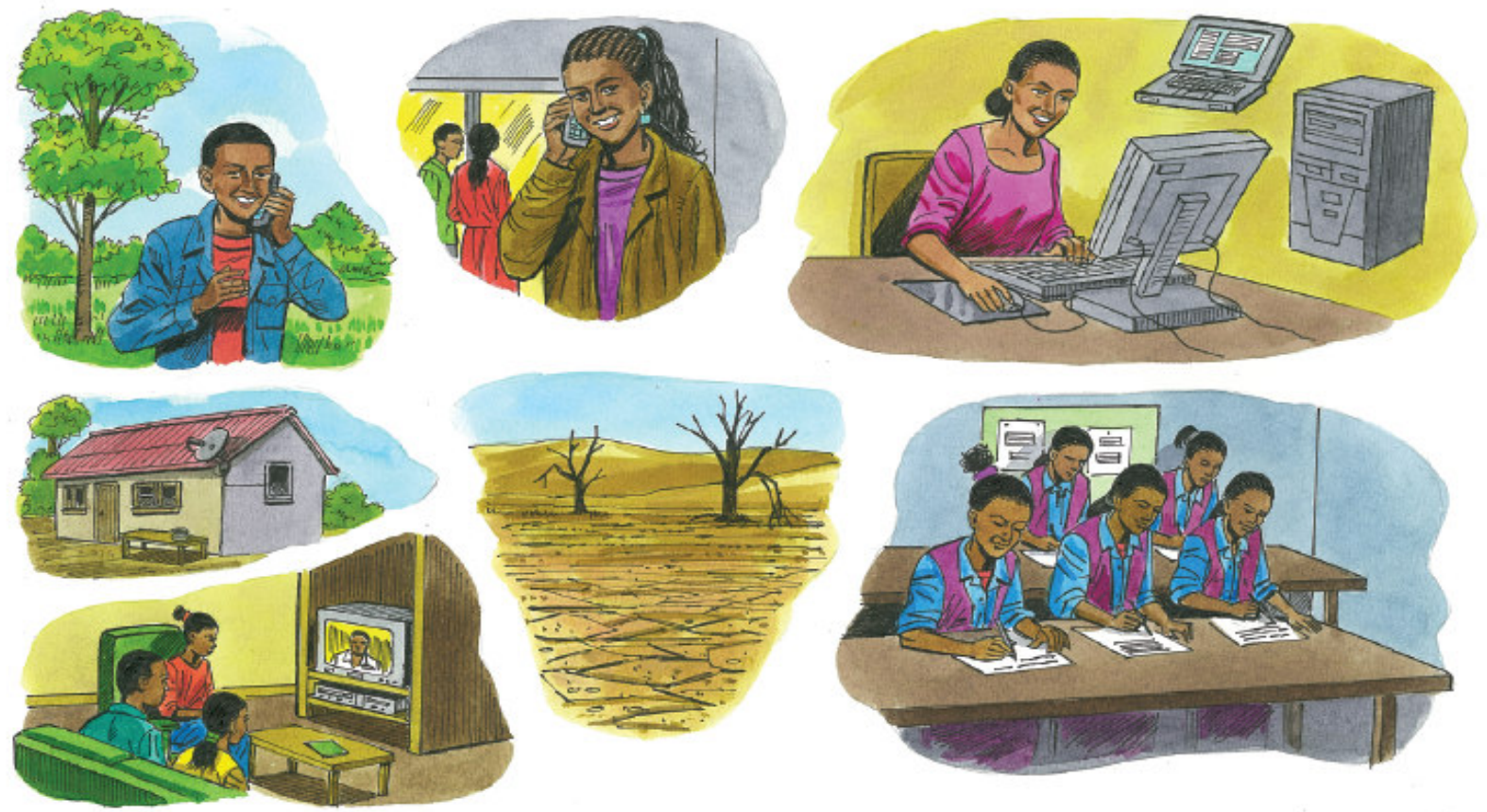

Extracted from Grade 12 English Textbook page 74

Second, as it can be seen from Table 3, find the difference communicative contents and activities are represented in seven different units namely: unit one, two, three, five, seven, eight and nine. It has been given equal share with picture narration communicative contents and activities in Grade 12 English Textbook. In the 'find the difference' activities students are asked to compare and contrast the similarities and differences of the given pictures. For example, students in pairs may have a picture of a boy reading a text-book and a picture of a girl watching television. Therefore, the students in pairs will discuss the similarities and difference of the pictures. In the case of find the difference activities in the Textbook, most of the activities are interesting. There are different pictures with different activities so that they are appropriate to order students in order to differentiate the similarities and the difference in the given pictures. Besides, the activities can let students describe the similarities and the differences using their own words, so the activities can enhance the oral communication skills of students through repeated practice of describing find the difference activities. However, the activities are interesting, the problem is the instruction which ordered students to do with the activities. Because most of the instructions order students to listen to their teacher's reading of the given passage and to match the expressions with the pictures, which is very simple and not appropriate to the age and grade level of students. The instructions don't encourage students to describe find the difference activities using their own words in order to enhance their oral communication skills.

Finally, as it is seen in table 3, interview activities are represented in three units of the Textbook which are Unit three, seven and eleven. Conducting interview with people gives students a chance to practice their speaking ability not only in the class but also outside and helps them becoming socialized. After interviews each student can present his /her study to the class. Moreover, students can interview each other and introduce his/her friends to the class. Doing this both the interviewer and interviewee will share a good experience. It is a good idea that the teacher provides a rubric to students so that they know what types of questions they ask/ what paths 
to follow, but students should prepare their own interview questions. Therefore, interview activities are very important and appropriate to Grade 12 students, but the interview activities in Grade 12 English Textbook don't consider its huge role. Because the least represented activities compared with other functional communicative contents and activities are the interview activities. Besides, most of the represented activities don't encourage students to conduct interview and to present it in classroom rather the activities are represented for the sake of inclusion. For evidence, all the interview activities are presented below:

\section{Go back to the interview with Kate Winslet. Write the dialogue between her and the} journalist.

- Only include what was said in the interview - not the background information the journalist gives about Kate Winslet.

- Some of her words are in reported speech in the text and some are in direct speech. You must write her all her words in direct speech in the dialogue.

- The journalists questions are all reported, so you must change them to direct speech.

- You may have to make up some missing questions.

Begin like this:

J: Could you begin by telling me where you originally come from?

KW: Yes, I was born in England and I grew up there.

\section{Go back to the interview with Kate Winslet. Write the dialogue between her and the journalist.}

- Only include what was said in the interview - not the background information the journalist gives about Kate Winslet.

- Some of her words are in reported speech in the text and some are in direct speech. You must write her all her words in direct speech in the dialogue.

- The journalists questions are all reported, so you must change them to direct speech.

- You may have to make up some missing questions.

Begin like this:

J: Could you begin by telling me where you originally come from?

KW: Yes, I was born in England and I grew up there.

Extracted from Grade 12 English Textbook

\section{Summary, Conclusions and Recommendations}

\subsection{Summary of Major Findings}

The study revealed that different communicative contents and activities were included in Grade 12 English Textbook. Besides, data collected from teachers and document analysis are presented respectively below so as to justify the data from students Therefore, it can be concluded that different communicative contents and activities are available in Grade 12 English Textbook.

The respondents mentioned some of the communicative contents and activities from Grade 12 English Textbook that they thought were like different contents and activities related with pictures, role-play, discussion, debate, dialogue, conversation and so on.

\subsection{Conclusions}

The study revealed that that different communicative contents and activities were found in Grade 12 English Textbook as confirmed by three different results, which are based on questionnaire data from students, semi structured interview data from two English teachers and data from document analysis. This doesn't mean that the availability of communicative contents and activities can make English language teaching and learning effective and only the availability can't make the Textbook appropriate to students, because the contents and activities should be organized and designed sequentially.

\subsection{Recommendations}

Some of the communicative contents and activities presented in Grade 12 English Textbook should be revised and replaced by the authentic communicative contents and activities that can expose students to use the language out of EFL classroom to perform certain communication and academic functions. Therefore, MOE (Ministry of Education) and other concerned bodies should take due attention to revise textbook considering communicative contents and activities to promote students communicative competence. Last, the EFL teachers should adopt 
materials before putting it into classroom context by considering different authentic examples and illustrations to promote EFL students communicative competence.

\section{References}

Cunning worth, A. (1995). Choosing your course book. London: Heinemann.

FDRE, MoE (2003 E.C). English for Ethiopian Grade 12 students Textbook: England, Pearson Education Ltd.

Grant (1990). Textbooks and Alternative Materials. Journal of Education. Vol 172, NO 2 PP

Grant, N. (1987). Making the most of your textbook, New York Longman Inc.

Graves, K. (2000). Designing language course: A guide for teachers. Boston: Heinle.

Hailu Kebede (2011). An exploration of Teaching Oral Skills through Communicative Activities Unpublished MA thesis unpublished). Addis Ababa Addis Ababa University.

Hutchinson, T. and Torres, E. (1994). The textbook as agent of change. ELT journal vol. 4814. PP

Hutchinson, T and waters, A. (1987) English for specific purposes. Cambridge: CUP.

Jones, I (1999). Criteria in selecting English Language Teaching Course book: Teachers' and Students' point of view (unpublished master's thesis). Cukurova University, Adana, Turkey.

Kothari (2004). Research methodology methods and techniques. New Delhi: New Age International Ltd.

Lakeckew Mulat (2003). Teachers' Attitudes towards Communicative Language Teaching and Practical Problems in its Implementation (unpublished MA thesis). Addis Ababa University.

Melaku Dumessa (2002). An Investigation of English Language Teachers' reading lesson Presentation in terms of the new course book for grade 9 in some selected government Secondary schools in Addis Ababa (unpublished MA thesis). Addis Ababa University.

Richards, J.C. \& Schmidt, R. (2010) Longman dictionary of language teaching and applied Linguistics. Harlow, UK: Longman.

Richards, J.C (1994). Reflective teaching in the language classroom Cambridge: CUP.

Richards, J.C (2001). Curriculum development in language teaching New York: Cambridge University Press.

Richards, J.C (2001). The role of textbook in a language program. Cambridge: Cambridge University Press.

Richards, J.C (2006). Communicative language teaching today Cambridge: Cambridge University Press. 